\title{
Aryl hydrocarbon receptor overexpression in miniaturized follicles in female pattern hair loss*
}

\author{
Paulo Müller Ramos ${ }^{1}$ \\ Ana Carolina Pereira Martins ${ }^{2}$ \\ Mariângela Esther Alencar Marques²
}

\author{
Gabrielli Brianezi² \\ Márcia Guimarães da Silva ${ }^{2}$ \\ Hélio Amante Miot ${ }^{1}$
}

DOI: http://dx.doi.org/10.1590/abd1806-4841.20175150

\begin{abstract}
The etiopathogenesis of female pattern hair loss is still poorly understood. In addition to genetic and hormonal elements, environmental factors could be involved. The aryl hydrocarbon receptor is expressed in keratinocytes and can be activated by environmental pollutants leading to alterations in the cell cycle, inflammation, and apoptosis. Here we demonstrate the overexpression of nuclear aryl hydrocarbon receptors in miniaturized hair follicles in female pattern hair loss.
\end{abstract}

Keywords: Alopecia; Dioxins; Receptors, aryl hydrocarbon

Female pattern hair loss (FPHL) is caused by a progressive hair follicle miniaturization and premature termination of anagen. ${ }^{1}$ Although its etiopathogenesis is not completely understood, little evidence supports the initial concept that the condition is a purely androgen-dependent entity. Recent data indicate a multifactorial etiopathogenesis. ${ }^{2,3}$

In addition to genetic and hormonal elements, environmental factors like solar exposure and smoking may be involved. ${ }^{2} \mathrm{How}$ these elements could take part in the evolution of the disease is not clear. We hypothesized that some receptors could intermediate environmental signals and trigger intracellular events that may participate in this process.

The aryl hydrocarbon receptor (AHR) is expressed in keratinocytes and can be activated by environmental pollutants (e.g. dioxin), lipids, or by natural compounds deriving from ultraviolet radiation or Malassezia spp. activity. When activated, these receptors migrate from the cytoplasm to the nucleus and bind to a xenobiotic responsive element that induces the transcription of the target genes. ${ }^{4,5}$ Its activation can lead to alterations in the cell cycle, inflammation, and apoptosis, which in turn could interfere in the hair follicle cycle. ${ }^{6}$
Despite being widely expressed in the skin, AHR has not yet been studied in the hair follicle, nor has its role in FPHL physiopathology been examined. We propose to evaluate the differential expression of AHR in terminal and miniaturized hair follicles of patients with FPHL.

We performed a cross-sectional study involving 17 female patients with FPHL (clinical and anatomopathological diagnosis) from our dermatology outpatient unit. Between 2009 and 2012, the patients' scalps were biopsied (punch $4 \mathrm{~mm}$ ) for diagnostic purposes. The study was approved by the Institutional Research Ethics Committee.

Transversal sections (thickness of $3 \mu \mathrm{m}$ ) close to the follicle bulge region were submitted to histochemistry (hematoxylin-eosin) and immunohistochemistry (AHR Antibody).

Immunohistochemical staining was performed using the avidin-biotin-peroxidase method. ${ }^{7}$ We used commercially available monoclonal antibodies (1:100 dilution): AHR - aryl hydrocarbon receptor antibody; ab2770; Abcam.

Individualized follicles were photographed in a standardized manner under 20x magnification. Follicles were considered terminal when shaft diameters were thicker than their inner root sheaths and miniaturized when the shaft was thinner.

Received on 17.09.2015

Approved by the Advisory Board and accepted for publication on 01.04.2016

* Work performed at Faculdade de Medicina de Botucatu - Universidade Estadual Paulista - (FMB-UNESP) - Botucatu (SP), Brazil. Financial support: none.

Conflict of interest: none.

1 Department of Dermatology and Radiotherapy - Faculdade de Medicina de Botucatu - Universidade Estadual Paulista "Júlio de Mesquita Filho" (FMBUNESP) - Botucatu (SP), Brazil.

2 Department of Pathology - Faculdade de Medicina de Botucatu - Universidade Estadual Paulista “Júlio de Mesquita Filho" (FMB-UNESP) - Botucatu (SP), Brazil.

(C)2017 by Anais Brasileiros de Dermatologia 




FIGURE 1: Transversal cuts of hair follicles stained with immuno-histochemistry of AhR. A. Terminal follicle. B. Miniaturized follicle

TABLE 1: Mean (SD), nuclear (HSCORE), and cytoplasmic AHR expression in subjects with FPHL $(n=17)$.

\begin{tabular}{llll} 
Variable & Terminal & Miniaturized & p-value \\
\hline HSCORE $^{\mathrm{a}}$ & $123.8(39.0)$ & $142.8(32.5)$ & $<0.01$ \\
Cytoplasm $^{\mathrm{b}}$ & $55.8(9.6)$ & $51.6(8.1)$ & $<0.01$
\end{tabular}

a AHR nuclear staining score; ${ }^{\text {b }}$ Cytoplasmic staining for AHR (subtracted the mean value of the histogram for the color from a representative region of the cell's cytoplasm)

AHR nuclear staining was estimated using HSCORE for each follicle category and in each subject. ${ }^{8}$ The quantitative image analysis of the cytoplasmic AHR immunostaining was estimated by subtracting the mean value of the histogram for the color from a representative region of the cell's cytoplasm, using photographed sections of the slide, using the software Image J 1.47.

\section{REFERENCES}

1. Ramos PM, Miot HA. Female Pattern Hair Loss: a clinical and pathophysiological review An Bras Dermatol. 2015;90:529-43.

2. Su LH, Chen LS, Chen HH. Factors associated with female pattern hair loss and its prevalence in Taiwanese women: a community-based survey. J Am Acad Dermatol. 2013;69:e69-77.

3. Messenger AG. Hair through the female life cycle. Br J Dermatol. 2011;165:2-6.

4. Esser C, Bargen I, Weighardt H, Haarmann-Stemmann T, Krutmann J. Functions of the aryl hydrocarbon receptor in the skin. Semin Immunopathol. 2013;35:677-91.

5. Gaitanis G, Magiatis P, Stathopoulou K, Bassukas ID, Alexopoulos EC, Velegraki $A$, et al. AhR ligands, malassezin, and indolo[3,2-b]carbazole are selectively produced by Malassezia furfur strains isolated from seborrheic dermatitis. J Invest Dermatol. 2008;128:1620-5.

6. Nguyen NT, Hanieh H, Nakahama T, Kishimoto T. The roles of aryl hydrocarbon receptor in immune responses. Int Immunol. 2013;25:335-43.

7. Hsu SM, Raine L, Fanger H. Use of avidin-biotin-peroxidase complex $(A B C)$ in immunoperoxidase techniques: a comparison between $A B C$ and unlabeled antibody (PAP) procedures. J Histochem Cytochem. 1981;29:577-80.

8. Ishibashi H, Suzuki T, Suzuki S, Moriya T, Kaneko C, Takizawa T, et al. Sex steroid hormone receptors in human thymoma. J Clin Endocrinol Metab. 2003;88:2309-17.
Data were compared between the groups according to the follicular category (miniaturized or terminal) using the generalized linear mixed-effect model. The correlation between HSCORE and cytoplasmic staining intensity (AHR antibody) was obtained using Pearson's linear correlation coefficient $(r)$. A $p$ value $\leq 0.05$ was considered significant.

We evaluated 277 follicles, $42 \%$ of which were terminal and $58 \%$ were miniaturized (Figure 1)

Miniaturized follicles disclosed a greater expression of nuclear AHR and a lower expression of cytoplasmic AHR (Table 1). There was a negative correlation between nuclear and cytoplasmic expression of AHR $(r=-0.37 ; p<0.01)$.

These findings suggest the activation and migration of AHR to the nucleus in miniaturized FPHL follicles.

The mechanisms through which AHR is involved in miniaturization are not clear. One possibility is the promotion of the apoptosis process. AHR favors keratinocyte apoptosis by CD95 (Fas) and TRAIL death receptors. ${ }^{9}$ Apoptosis is a central element in the regulation of hair follicle regression and may be involved in the miniaturization process. ${ }^{10}$

This was the first study to assess AHR in hair follicles and FPHL. Further investigations are necessary to confirm this association and to explore environmental factors that could activate AHR in the follicle. $\square$
9. Stolpmann K, Brinkmann J, Salzmann S, Genkinger D, Fritsche E, Hutzler C, et al Activation of the aryl hydrocarbon receptor sensitises human keratinocytes for CD95L- and TRAIL- induced apoptosis. Cell Death Dis. 2012;3:e388.

10. Ramos PM, Brianezi G, Martins AC, da Silva MG, Marques ME, Miot HA. Apoptosis in follicles of individuals with female pattern hair loss is associated with perifollicular microinflammation. Int J Cosmet Sci. 2016;38:651-654.

How to cite this article: Ramos PM, Brianezi G, Martins ACP, Silva MG, Marques MEA, Miot HA. Aryl hydrocarbon receptor overexpression in miniaturized follicles in female pattern hair loss. An Bras Dermatol. 2017;92(3):430-1. 